\title{
Revista
}

Pensenmientito y Aebín

\section{Crítica a la filosofía de la Liberación}

Jony-Alexis Rengifo-Carpintero ${ }^{1}$

Carmen-Helena Díaz-Caicedo²

Fecha de recepción: 07 de enero de 2021

Fecha de aprobación: 10 de marzo de 2021

\section{Resumen}

El artículo es una reflexión crítica sobre el fenómeno ideológico del sur, denominado, Filosofía de la Liberación. En este se analizarán tres aspectos: primero, el uso exacerbado que los autores hacen de la reflexión histórica por encima de todo acontecer positivo; segundo, su pretensión doxológica que termina siendo una judaización del pensamiento en Latinoamérica; y, tercero, la terrible paradoja que esta forma de pensar ofrece: la aplicación de un método decolonial implica necesariamente un lugar de poder desde donde lo oprimido juzga la historia y el mundo de la vida del opresor. La metodología propuesta para dicho examen es la deconstructiva, acción de orientación que nos permitirá poner en evidencia las contradicciones conceptuales de tal movimiento. Para ello, el texto hace una reflexión sobre dos movimientos que le dieron origen, la Pedagogía Crítica y la Teología de la Liberación. Finalmente, el texto evidencia las contradicciones de esta forma de pensar, al presentar la acción decolonial como norma a ser aplicable a todo proceso histórico de exclusión, marginación y colonización, produciendo un discurso de poder el cual se ha empeñado en rechazar.

Palabras clave: filosofía; historia; ontología; pedagogía; teología.

\footnotetext{
${ }^{1}$ M. Sc. Escuela Superior de Administración Pública (Cali-Valle del Cauca, Colombia).

${ }^{2}$ Asociación Eslabón Cultural de Cali (Cali-Valle del Cauca, Colombia). 


\section{Criticism of the Philosophy of Liberation}

\section{Abstract}

The article is a critical reflection on the ideological phenomenon of the South, called, Philosophy of Liberation. In this, three aspects are analyzed: first, the exacerbated use of historical reflection above all positive happenings; Second, his doxological pretension that ends up being a Judaization of thought in Latin America; And third, the terrible paradox that this way of thinking offers: the application of a decolonial method necessarily implies a place of power from where the oppressed judges the history and the world of the life of the oppressor. The proposed methodology for this examination is the deconstructive, orientation action that will allow us to highlight the conceptual contradictions of such a movement. For this, the text makes a reflection on two movements that gave origin to him, the Critical Pedagogy and the Liberation Theology. Finally, the text shows the contradictions of this way of thinking, presenting the decolonial action as a norm to be applicable to any historical process of exclusion, marginalization and colonization, producing a discourse of power which has been determined to reject.

Keywords: history; ontology; pedagogy; philosophy; theology.

\section{Para citar este artículo:}

Rengifo-Carpintero, J.-A., Díaz-Caicedo, C.-H. (2021). Crítica a la filosofía de la Liberación. Pensamiento y Acción, 31, 1-26.

Esta obra está bajo licencia internacional Creative Commons Reconocimiento 4.0 


\section{Introducción}

El siguiente escrito es una problematización del fenómeno académico intelectual denominado filosofía de la "liberación". El trabajo será desarrollado del siguiente modo: en primer lugar, se hará una reflexión sobre dos de los campos disciplinarios que le dieron origen, la pedagogía crítica y la teología de la liberación. En segundo lugar, el pensamiento vuelto escritura habrá de devenir problemático en un enfrentamiento con los supuestos conceptuales de esta forma del pensar, especialmente evidenciando la paradoja que resulta de aplicar el método decolonial que termina instituyéndose en un discurso de poder, el de la periferia. Finalmente, se concluirá que la filosofía de la Liberación no es posible debido a: primero, el academicismo doxológico judío que pervive en su arquitectura teórica; segundo, la falta de entendimiento que hay de otras ontologías, o formas de ser, pensar y sentir el mundo, y que son juzgadas como filosofía, para lo cual se pondrán, a modo de ejemplo, culturas sobre las cuales tenemos un acercamiento: la ontología indígena, negra y china. Por último, si se hace una deconstrucción histórica del proceso de dominación sobre los oprimidos, tal proceso se debe hacer incluso al interior de pueblos que le dieron origen al continente, de modo tal que lo indígena y lo negro, antes de la conquista, también habrán de ser puestos en crisis, debido a que al interior de estos también se dieron procesos de dominación, exclusión, marginación, imposición y conquista.

\section{Metodología}

Para esta reflexión, si ha de hablarse de una metodología, está habrá de ser completamente deconstructiva. La deconstrucción sobre los presupuestos teóricos y conceptuales del academicismo autodenominado filosofía de la Liberación en Latinoamérica, es una necesidad con el ahora. Porque el ahora no necesariamente ha de enraizarse en la historia. El ahora también es un emerger problemático siempre presente, aunque dinámico y fluido. Pese a que está emparentado con el ayer lo constituye la positividad de la acción. Es, ante todo, una construcción desde la acción cotidiana, instante a instante. Por lo que, agotarlo en el ayer lo vacía de su acontecer positivo, aunque problemático, y le quita el flujo contextual de la 
responsabilidad ética, estética y existencial a los societarios. En el discurso en cuestión, nadie es responsable de su situación social, vivencial o existencial: la historia de la opresión lo es: el lugar de procedencia, los lazos consanguíneos, el contexto societal, afectivo, emocional, no han de ser responsabilidad de nadie, por lo que, toda incapacidad es justificada. La historia de la opresión justifica la condición existencial del ser aquí y ahora marginal. El pensar marginal, el sentir marginal, el existir marginal, la cultura de lo marginal no son situaciones societales de hoy, están ancladas al "pasado"; por lo que, el societario está excusado de su acontecer. Nadie es responsable de nada, porque su situación histórico contingente es culpable de todo. En el contexto social actual se pasó de culpabilizar a los dioses o demonios de los sufrimientos del hombre y se trasladaron tales padecimientos a la historia. La cuestión central es, ¿no es la decolonialidad un discurso de poder, el de la periferia?

\section{Surgimiento}

La filosofía de la liberación ha sido una corriente filosófica cuyo acontecer histórico puede rastrearse desde los años sesenta en el contexto de una situación social y política, internacional, de convulsión. En su advenimiento, el pensar desde otras disciplinas sirvió para catapultar una nueva forma de reflexionar desde el sur, una filosofía de la "liberación": la teología de la liberación, la pedagogía crítica y la literatura del realismo mágico, la teoría funcionalista han sido la piedra angular de un movimiento que se presentará como propio de los países de la periferia (Dussel, 2016).

En su estructura interna, esto es, en su elaboración conceptual, han de hallarse los vestigios conceptuales de unos pensadores "europeos" que han constituido su corpus teórico, desde una nueva reinterpretación, la de esta corriente de pensamiento: un pensar desde los márgenes. La dialéctica Hegeliana, el materialismo histórico de Marx, la ética existencialista de Levinas, y en algunos, los presupuestos teóricos del psicoanálisis de Freud son el fundamento epistemológico de sus reflexiones: las palabras, el lenguaje, el método, los problemas, las soluciones, desafortunadamente, beben de uno u otro modo de estas fuentes. 
Hay quienes ponen el principio de diferenciación entre las distintas vertientes de la FL en la mediación analítica preferentemente empleada para la reflexión filosófica desde y sobre la práctica liberadora. Así es como Raúl Fornet-Betancourt distingue entre dos principales enfoques: el éticocultural (de Kusch, Cullen, Scannone y otros) y el que, sin ser marxista, estaría "orientado por el marxismo" (por ejemplo, Dussel) [...], como también su enriquecimiento con contribuciones de otras filosofías, como son la de Xabier Zubiri (Ellacuría, Germán Marquínez Argote) o de Paul Ricoeur, Karl-Otto Apel y otros. (Dussel, Scannone). (Scannone, 2009, p. 62-63)

Reviste de gran importancia señalar que, en su ejercicio de hacer filosofía, de pensar los problemas latinoamericanos desde el sur, una sola forma de investigar se erige como quantum de posibilidad para éstos, el análisis histórico del acontecer social. La reflexión constante, sistemática, y continua sobre la historia como tapis epistemológico de verdad, sobre: cómo se ha construido la identidad en Latinoamérica, cómo ha de ser pensado, entendido y reconstruido el mundo de la vida desde lo oprimido:

Hoy se trata no sólo del pobre como oprimido, sino como excluido de la vida y convivencia dignas $y$, no pocas veces, de la vida y convivencia a secas. Dicha opción por los pobres y excluidos es, sin embargo, universalmente humana, porque es de hecho la opción por lo humano y la dignidad humana en cuanto tal. De ahí que dichas situación y opción se constituyan entonces en lugar hermenéutico del filosofar. Se trata del lugar desde donde se interpretan y disciernen no sólo la actualidad histórica latinoamericana, sino también toda la realidad sin más. (Scannone, 2009, p. 67)

¿Qué procedimientos habrán de utilizarse para pasar de un colonialismo del pensamiento simbólico y material europeo, a un decolonialismo desde la periferia? Es, al parecer, la reconstrucción histórica el único mecanismo para reencontrar el camino perdido. 
Se ha hecho del ejercicio histórico, del volver sobre los recuerdos, de la nostalgia por el pasado, de una acción nemotécnica sobre el ayer, la piedra angular del conocimiento. Pero, y si no es la historia, entonces, ¿qué método habrá de ser?, ¿qué hace de la historia el lugar de emergencia de la verdad?, ¿sin el plano del existir de la historia, un pensar desde Latinoamérica no puede emerger?, ¿es la nostalgia del pasado tan fuerte que no se puede vivir el presente de otro modo?, ¿la historia descubre la "verdad" o es, más bien, un ejercicio de justificación de la propia impotencia?, ¿la historia de las ideas, de los acontecimientos, de los orígenes, de los documentos, de los monumentos, es principio rector?, ¿no hay otro modo de poder reflexionar, por ejemplo desde el ahora?, ¿qué se gana realmente, con el análisis histórico?, acaso ¿un proceso de sanación?, ¿qué hace de la reconstrucción crítica del pasado un ahora mejor, o por lo menos, la posibilidad de un mañana menos peor?, ¿qué enfermo, drogadicto, ha de recordar su pasado para poder auto-sanarse?

\section{Otra forma de hacer educación}

La pedagogía crítica es un modelo pedagógico surgido en los años 60 en Brasil con el educador Paulo Freire en su obra más representativa La pedagogía del oprimido (1971) en donde se hace del espacio llamado escuela, un espacio de reflexión crítico entre la subjetividad discursiva llamada educador y el actor dinámico denominado educando, en un doble sentido, a saber: a) hace que los actores sociales, educador y educando, se sientan partícipes activa y reflexivamente del proceso de enseñanza-aprendizaje, al articular sus propias vivencias a la dimensión educativa en el aula de clase. B) hace que las disciplinas escolares (Chervel, 1991) puedan ser comprendidas, esto es, enseñadas y aprendidas, no como un saber impositivo de carácter "euro-centrista" y excluyente; sino, por el contrario, como un saber práctico y dinámico que le aporta significativamente a la constitución del imaginario colectivo, tanto del educando como del educador, mediante la implementación del método deconstructivo y el dialógico. Acción que permite que los actores sociales redefinan la realidad de acuerdo con sus parámetros etno-culturales a través de la movilización dinámica de los fondos de 
saber (McLaren, 1991), que el educador, en calidad de agenciador, percibe y trae al espacio académico denominado aula de clases, del educando; éste, el estudiante, por su parte, en calidad de actor dinámico, lleva sus prácticas vivenciales y saberes tradicionales a ese lugar de encuentro e interacción llamado salón de clases. De tal modo, que el salón de clases pasa de ser un recinto cerrado o abierto de imposición sistemática del conocimiento, a uno de interacción, reciprocidad, de inclusión y de emancipación social donde afloran lenguajes etno-culturales propios, ideologías respetables y racionalidades innovadoras de mujeres, de negros, de latinos etc., que les permite transformar, cuestionar, evaluar y replantearse constantemente su mundo de la vida.

De ahí que, el método de Freire ahonde sobre tres momentos en el proceso de concienciación de los oprimidos frente a los opresores: a) en reconocimiento objetivo de la propia realidad histórica (Freire,1971); b) en la conciencia social crítica de tal reconocimiento, especialmente en la relación opresor-oprimido (1971); c) una acción de reflexión y praxis social de liberación (McLaren, 1991); la palabra, o mejor aún, decir la palabra propia a través del ejercicio crítico del diálogo en un proceso de interacción socio-educativo entre educador-educando como acto de unión, de encuentro y de recuperación de lo humano, hace de la alfabetización crítica una acción de reivindicación socio-política de los oprimidos (1971).

Hegel se hizo eternamente presente en este modelo, en tanto en cuanto, es su dialéctica entre el amo y el esclavo (Hegel, 1971) lo que reivindica el papel político de la conciencia del oprimido frente a la realidad material del opresor, liberando el último al primero a través de la movilización de la conciencia mediante el ejercicio del reconocimiento de la objetividad de la palabra reflexiva, del mundo socialmente compartido (Habermas, 1999) y de la historia propia y ajena motivacionalmente anclada en una historia del conflicto. Sin embargo, tal conflicto fue rebajado a una sola dimensión del existir, el modo de vida burgués; y se hizo del consumo, de la acción social de consumir, un placer social.

La pedagogía crítica creía, entonces, generar en el educando y en el educador la posibilidad de que éstos se transformen tanto a sí mismos, como a su contexto social y político, en subjetividades discursivas, y en intelectuales transformadores, 
emprendedores, capaces de asumir una actitud política, crítica y reflexiva frente al mundo (McLaren, 1991); gracias a que interiorizan un lenguaje de oposición crítico y reflexivo, sobre las adversidades y paradojas que trae consigo la ideología dominante, ya que llevan a cabo una praxis de protesta, en el terreno educativo, para transformar la realidad escolar en torno a sus vivencias.

De ahí que para uno de los pensadores más representativos, Peter McLaren el contexto educativo, en el proceso de enseñanza-aprendizaje, debía de pasar de la mera comprensión pasiva del conocimiento de la escuela de talante tradicional, neoliberal y conservadora, a una actitud de emprendimiento activa, participativa, crítica y reflexiva propia del estudiante y del profesor de talante revolucionario; Para este, estos han de comprender cabalmente la situación socio-político que enfrentan y la transforman crítica y reflexivamente a través de la inclusión pedagógica de su contexto social, mediante el empoderamiento de un discurso revolucionario. De modo tal, que se pensaba, era posible articular la reflexión lingüística dialógica y la praxis social-teórica, en la deconstrucción como método filosófico y de acción social, aplicado al ámbito académico, sobre el trasfondo de un contexto social opresivo y manipulador comúnmente compartido por todos los societarios.

La pedagogía crítica es una pedagogía en la que lo personal es entendido siempre como social, y lo social es insertado siempre en la historia a fin de poner de manifiesto el modo particular en la que ha sido producida la subjetividad y elegir los caminos por medio de los intereses de sexo, raza y clase tanto como por medio de otros intereses. (McLaren, 1991, p. 39)

\section{Debilidades de la pedagogía crítica}

La pedagogía crítica, más allá de su humanismo político revolucionario, no pudo prever que el fenómeno del mundo tecnológico habrá de agotar la figura del maestro, tornándose cada vez más gris, descolorida y caricaturesca; y que, en su muerte lenta y desaparición forzada, el educando habría de cobrar protagonismo. Será él hoy el verdugo de un proceso y de una figura, la del maestro. Situación que ha dejado al educando en un contexto de orfandad auto-producida; aunque, con dos padres sustitutos bien empoderados, la TV y la internet. Con el primero establece 
un solo modo de relación, el entretenimiento en un paquete de información específico, objetivo, el consumo. Con el segundo, su único modo de ser, un autista tecnológico: un consumidor drogado por la red, en interacción psíquica vía redes y co-constructor de un único universo: la estupidez vuelta imperativo social.

Los métodos propuestos: la relación dialógica educador-educando, el espacio académico vuelto un espacio de discusión, el pluralismo crítico como motor del proceso educativo, la movilización de los fondos de saber, en suma, la dimensión crítico-revolucionaria que debería poseer el acto educativo como quienes lo fundamentan el educador y el educando, indiscutiblemente han sido rebasados por una sola dimensión, la tecnología audiovisual: la imagen vuelta comicidad, la comicidad vuelta norma social y el mundo de la vida barrial, tribal, del educando, instituyéndose en institutivo desinstituyente de la legitimidad del espacio escolar (Corea, Lewkowicz, 1996). De ahí que, tal modelo, no logró prever que el internet habría de agotar el espacio físico al imponer un no-espacio, el virtual.

Ahora bien, en el llamado proceso de concienciación del que habla Freire, pueden notarse las siguientes falencias: a) La pedagogía crítica ha hecho de la historia un fetiche: abandono discursivo y sistemático de la responsabilidad ética, existencial y estética sobre el ahora; b) la situación del oprimido histórico niega la situación de marginalidad del ser social actual, es decir, la situación de opresión es culpa del pasado, por lo que el individuo es excusado de su propia situación social; c) la tecnología audiovisual y la Internet mataron tal ideal, la liberación nunca ocurrió, puesto que el societario ha sido castrado de su facultad de jugar (Poulan, 2008); hoy, más que nunca, no habrá de ocurrir: la Pandemia ha sido un buen ejemplo de ello. WhatsApp ha cercenado toda posibilidad de encuentro, haciendo del espacio académico un multiuniverso de flujo informativo, de modo tal, que opresor y oprimido se encuentran en una misma situación de interacción social: toda diferencia fue borrada. Desde luego, el advenimiento de un mundo ciberespacial borro este sueño dogmático; pues, ni la subjetividad crítica es posible, ni el intelectual trasformador existe, ni la praxis de protesta ha emergido; la red lo redujo todo a un clic: dar Like es un imperativo social. 
Así pues, la pedagogía crítica haciendo uso de constructos metodológicos filosóficos como la deconstrucción y el método dialógico, con miras a la construcción de un arco de sueño social (1991), invita a reflexionar, a desentrañar una problemática no solo de índole pedagógica, sino también, social y política que atañe a todos los sujetos educables, y que los invita a que sean seres comprometidos con su academia, con su país, con su herencia cultural. Por ello la manera más loable de remediar este absurdo consumismo tecnológico que nos aleja de la posibilidad de ser agentes de conocimiento y emprendedores, es adentrándonos en el mundo de la pedagogía crítica, expuesta por McLaren, llevada al espacio escolar y aplicada en el terreno de la enseñanza de la filosofía.

Desde luego este modelo pedagógico demasiado humano no contó, como anteriormente se expuso, con: primero, el imaginario colectivo de la masa amorfa de educandos latinos atrapados en la lógica de un mundo de la vida práctico, narcotraficante, que instituye a través de ritmos musicales como el Reggaetónu el. Trap, el estereotipo educativo del mafioso que triunfa ante los avatares de una vida trágica; segundo, la conquista del mundo de la vida burgués como justa medida de toda posibilidad existencial, el facilismo que este ideal de vida produjo, anuló toda ideología política, religiosa o cualesquier otra, del mundo de la vida de los societarios; tercero, la red, los OTM (Objetos Tecnológicos de Moda) y el ciberespacio, como instituyentes del único espacio de institución posible: situación ficticia de co-construcción social, se legitima la imagen vía chat, se deslegitima todo proceso de pensar reflexivo; cuarto, el advenimiento de la educación como un proceso de mercantilización disciplinario del saber, la educación se ha transformado en una venta de servicios informativos, vueltos paquetes académicos instruccionales; quinto, el agotamiento de la figura del maestro como poseedor de un saber, por la del estudiante consumidor de información: san Google como maestro de maestros; sexto, la reducción del mundo a una sola lógica, la del mundo global: el consumo hecho imperativo social: muerte de toda diferencia. 


\section{Otra mirada sobre la teología de la liberación}

Examinemos ahora, de un modo crítico, la otra corriente que sustentó la emergencia de la filosofía de la liberación, la teología de la liberación, desde el punto de vista de su incapacidad transformadora del acaecer cultural, política, económica y espiritual del pueblo como realidad social, pese a todos sus esfuerzos internos (eclesiales) y externos (misionales).

Partiremos de una hipótesis bastante simple: ¿cómo hablar de liberación, desde el contexto, precisamente, del judeo-cristianismo; es decir, desde el discurso histórico del opresor? Acaso se le puede olvidar al pueblo latinoamericano que él es el resultado de tres movimientos: a) los jesuitas, un movimiento de adoctrinamiento cultural que de un tajo borró las tradiciones míticas y ancestrales de los pueblos indígenas y negros; los franciscanos, o mendicantes, que le enseñaron a los pueblos a perpetuar felizmente su condición social de pobres, a la imagen judaica, de Jesús de Nazaret, de miserables, de pecadores, para perpetuar la condición salvífica de la iglesia Católica como agente rector y regulador de la vida del hombre: condición de perpetuidad de su poder; Y finalmente, la orden de la Santa Inquisición que persiguió, asesinó y excluyó a mujeres, Gitanos, negros e indígenas, por el simple hecho de poseer otra fe, otra cosmovisión, otro credo, otra forma de ver el mundo.

¿Quiénes fueron los artífices de esta conquista?, ¿Quiénes los fundadores y organizadores de esa iglesia? Conquista, fundación y organización fueron obra esencialmente de las órdenes mendicantes, y, séanos lícito insistir en el hecho, de las órdenes en cuanto órdenes precisamente. Hecho particular y muy digno de ser ponderado es que las Iglesias de la América española fueron fundadas por los religiosos mendicantes, independientemente del episcopado, cuya autoridad iba a estrellarse en los privilegios pontificios concedidos al clero regular. (Ricard, 2013, p.24)

Por lo anterior, este apartado será desarrollado del siguiente modo. En primer lugar, aclararemos en qué consiste el concepto de teología de la liberación. En segundo lugar, mostraremos los elementos reales que la teología de la liberación no asume en este supuesto proceso de "liberación". Por último, haremos evidentes las 
contradicciones flagrantes en que incurre tal teología, reduciendo al hombre a la terrible condición de siervo perpetuo, pobre por convicción y mendigo existencial. La teología de la liberación es un esfuerzo eclesiástico acontecido desde la iglesia Latinoamericana a partir de los años 60 en un esfuerzo de contextualización del Concilio Vaticano II, por intelectuales teólogos y pedagogos como: el Peruano, Gustavo Gutiérrez Merino, quién fue el primero en desarrollar una literatura sobre el tema: Hacia una Teología de la Liberación (1968) y Teología de liberación Perspectivas (1971). Otros autores destacados han sido el teólogo Brasileño Leonardo Boff, el Español Jon Sobrino, y el Chileno Pablo Richard. Otro sector, estuvo representado por los sacerdotes revolucionarios como el Colombiano Camilo Torres Restrepo y los Españoles Manuel Pérez Martínez y Gaspar García Laviana. Quienes intentaron emancipar al pueblo de los elementos de opresión doctrinales, ideológicos, políticos, sociales y económicos que aumentan las desigualdades sociales y las brechas adquisitivas entre los económicamente pobres y los financieramente ricos. En un ejercicio constante de denuncia de la historia de América como un ejercicio de imposición política de Europa hacia éstos.

En la teología de la liberación en el contexto de la iglesia en el continente suramericano, intenta reencontrarse con los desposeídos, con los desdichados, con los marginados, con los oprimidos, ya que en éstos habita la presencia de Cristo. De hecho, la real evangelización es un proceso eclesial-misional de unión de Dios con el pueblo, es Jesús el maestro él que enseñó sobre el encuentro fraternal con los pecadores, los pobres, los necesitados, y es este el mensaje de tal teología.

El movimiento Eclesial de la Teología de la Liberación, es más un encuentro de asombro de la iglesia institución con el pueblo, que un proceso de descubrimiento de las necesidades reales del pueblo de parte de la eclesia; esto quiere decir, que es el pueblo el que le recuerda a la iglesia el valor espiritual del evangelio de Jesús Cristo, y no a la inversa. De hecho, el autor Álvaro Quiroz Magaña en su texto titulado Eclesiología en la Teología de la Liberación señala lo siguiente "Fuimos a ellos a llevarles el evangelio de la liberación y descubrimos que éramos evangelizados por ellos" (Magaña, 1980). De ahí que, tal discurso de la iglesia a favor de la liberación de todas las formas de alienación de los individuos al interior 
de sus pueblos no fue un acontecimiento acaecido por el propio esfuerzo del clero, sino, que surgió en respuesta a las formas de organización sociales y comunales que luchaban por la reivindicación de la emancipación del ser humano etnodiferente: el indio, el negro, el mulato, el mestizo, el zambo, la mujer, el homosexual. Ahora bien, en la teología de la liberación hay varias cuestiones que parecen pasar por alto sus defensores, pero que a nuestro modo de ver revisten de una importancia significativa, a saber: desde este contexto conceptual ¿Quiénes son los tan llamados pobres, desposeídos, marginados y oprimidos de la sociedad?, ¿qué hace que se les confiera tales denominaciones?, ¿qué aspecto sociológico, psicológico, y hasta existencial comportan éstos, para darles semejantes denominaciones?, ¿० es que se les llama así por el hecho fáctico de sus carencias económicas?, ¿ ¿lo será tal vez por el modo en que históricamente los pueblos Latinoamericanos se han constituido, a través de procesos de aculturación, adoctrinamiento e imposición cultural eurocentrista-eclesial?

En lo social, la Teología de la Liberación fue impactada fuertemente por la pobreza de América Latina. Pero, no simplemente por el hecho de que existe pobreza; sino, porque esa pobreza fue "sentida" -subrayo que se trata de un asunto de sensibilidad-, por un lado, como un escándalo intolerable dado que América Latina era un continente masivamente cristiano y católico, i por otro, como un estado que se podía superar, porque la modernidad occidental había descubierto los medios para lograr el desarrollo económico, político y social de los pueblos, como se podía ver en el Norte. Así, se mezclaban en el modo de "sentir" la realidad de la pobreza dos sensibilidades: una, propia de la fe; la otra, de la modernidad. Por esta segunda, entraba en la Teología de la Liberación el talante progresista, típico de los años 50 y 60 del siglo pasado, que marcó también, en alguna medida, al vaticano II. (Silva, 2009, p. 94)

Si esto es así, vale la pena señalar, entonces, que tal movimiento de liberación cae en una flagrante contradicción lógica en cada uno de los aspectos señalados, estas son: si la teología de la liberación lo que intenta es llevar a cabo un proceso de reivindicación de ciertos actores sociales que han sufrido procesos de 
adoctrinamiento severos, históricamente, lo primero que ella habría de hacer sería auto-replantearse la cuestión de ser un movimiento teológico de corte eclesial, debido a qué esta parte de un hecho dogmático falso: la consideración de los documentos del antiguo y del nuevo testamento como palabra de Dios, o sea, como libros Sagrados, cuando es un hecho bien conocido por un número reducido de intelectuales e historiadores, que tales libros no son más que un plagio sistemático realizado por el pueblo judío, de ciertos relatos sumerios, egipcios y griegos, según los textos mitológicos antiguos de cada uno de estos pueblos: a) la idea de un Dios único y sin nombre, tal noción se halla en la mitología egipcia, africana e hindú: Atun (Egipto), Olodumari (Yoruba, África), Brahama (India); b) la noción de un dios que posee tres naturalezas: creadora, conservadora y trascendental (padre, hijo y espíritu) propia de la india en las personas de, Brahama, Vishnu y Shiva; c) la idea de un dios hijo que salva a la humanidad y predica el amor, noción retomada del dios egipcio Horus, del dios hindú Krishna, del dios persa Mitra, y del dios africano Olodum; d) El juego cósmico entre una naturaleza benéfica Yahave, vuelto posteriormente Joshua, y una maligna (Luz Bel, Satanás) es retomada del universo cósmico del Zoroastrismo (Persia) en la idea de Aura-Mazda (el bien, el amor) y Angri-Manyu (el mal, el odio); e) los mandamientos plagiados del libro Egipcio de los Muertos; $f$ ) el nacimiento de un Dios-hombre del vientre de una virgen (Rama, Krishna, Osiris, Mitra); g) los conceptos de bautismo, muerte y resurrección, retomados de todos los cultos iniciáticos antiguos: el orfismo, el hermetismo, el brahmanismo, el eleusismo, etc.

La Teología de la Liberación pretende "liberar" desde la malignidad de un movimiento histórico político-religioso de extermino, exclusión y marginación, prácticas ancestrales enteras. Desde el siglo XVI los movimientos de contrarreforma católicos: la orden de los Jesuitas, el movimiento mendicante (Franciscano) y la inquisición, actuaron como movimientos de reestructuración doctrinal eclesial con el claro fin de adoctrinar a los pueblos conquistados por las bancas de España, Inglaterra y Francia. África, América e India se convertirán en co-extensiones ideológicas de los imperios de origen blanco, Ario, pero de mentalidad semita (Ashkenazis), dándole origen a un híbrido moral llamado judeo-cristianismo: su 
meta, el dominio político-religioso; su acción social, el adoctrinamiento cultural. Los Jesuitas educan, los franciscanos sanan y la inquisición purga. Los primeros aculturizan a los pueblos vendiendo la idea de un Dios inmaterial, conceptual y bondadoso; lo que deja sin posibilidad de escucha y resignificación al mundo sociocultural del otro, a los negros, los indios, los mulatos y los mestizos, pues todos los cultos que estos pueblos profesan dan cuenta de unas prácticas generalmente consideradas demoníacas. Los segundos, adoctrinan a los pueblos vendiendo la idea de la pobreza y la enfermedad como signos físicos de un pecado original al que sólo se sale por la gracias divina (Agustín, 1980), pero que paradójicamente representa el signo manifiesto de los elegidos por Dios, la pobreza es señal de humildad a la imagen y semejanza de Cristo. Ser pobre es ser cristiano. La parábola del hombre rico y el pobre Lázaro se instituye como pedagogía eclesial, reforzada por la frase de (Jesús) en el sermón del monte: benditos los pobres porque de ellos es el reino de los cielos. Dios salva y se dirige exclusivamente a los pobres. Los terceros purifican el alma de los pecadores en los suplicios del tormento santo. Se hace de la tortura una acción didáctica de redención espiritual. El resultado: unas confesiones que reivindican el papel activo de Satanás en el mundo, por más que el torturado ni siquiera crea en él, o ni si quiera tenga en cuenta tal idea en la constitución imaginaria del mundo socio-cultural de su pueblo.

Las prácticas de cultos africanos o indígenas caen ante la espada de la racionalidad de una iglesia que educa, civiliza y evangeliza. Se educa a los pueblos bárbaros para un solo fin: que aprendan a ser mano de obra calificada: el esclavo es esclavo por condición natural. Se civiliza a los pueblos para que aprendan a ser una sola cosa: receptores del mundo semítico-europeo, las propias tradiciones son vestigio de un saber incipiente, infantil. Se evangeliza a los pueblos porque: estos son como niños en una evolución social ascendente donde el Ario, híbrido de una cultura judía, es la medida que juzga toda medida. Por lo tanto, se instituyen unos modos de ser y de obrar, cristiano-ario-semitas. Se impone en el imaginario colectivo del negro, del indio, del mestizo, del zambo, del cuarterón, de la mujer, del homosexual un estereotipo de belleza: un Jesús de Nazaret Ario, de ojos azules, de cabello rubio y que se dirige exclusivamente a los desposeídos, parias y pecadores. El sermón del 
monte es su currículo enseñable. La compasión su acción pedagógica mortal, el aniquilamiento de la propia formación en pos de una vida excelsa, positiva. (Nietzsche, 2000).

Además de lo anterior, tal movimiento carece de un fundamento emancipador real, ya que las categorías conceptuales a través de las cuales piensa la acción liberadora no hacen más que movilizar odios, resentimientos y rencores en aquellos que deberían hacer de su historia trágica un episodio cerrado para aprender a hacer de su historia actual un momento cósmico único. Al contrario, la teología de la liberación o mejor, el discurso eclesial sobre la supuesta teología de la liberación no hace más que ahondar las brechas sociales entre los económicamente ricos y poderosos, y los económicamente pobres y desposeídos sociales. Esto quiere decir que, desde este discurso el pobre, el desposeído, el marginado lo es por las condiciones económicas que éstos profesan, pero en ningún momento se tienen en cuenta categorías más elocuentes que establecen otra forma de asumir la realidad de alguien que se auto-presente, o auto-considere como pobre o desposeído, estas pueden ser categorías tales como: pobreza en tanto carencia afectiva, emocional, cultural, social, psicológica, mental etc. Todas, categorías que nada tienen que ver con las condiciones materiales de un pueblo. $Y$ menos aún, que generan unas fronteras sociales tan grandes. Porque, a quién se le ha dicho que es un marginado, un pobre, un desposeído jamás elaborará un discurso distinto al del resentimiento social. Luchar por la reivindicación de un acto histórico de esclavitud, desposesión o aculturación, no es lo mismo que realizar un discurso auto-marginal contestatario de auto-alienación.

La teología de la liberación fosiliza, ancla, atornilla al individuo en un acontecimiento histórico trágico eterno. El individuo latinoamericano es asumido desde la lógica inherente de su condición social: la de actor social oprimido por un proceso de alienación histórico cultural que no le permite seguir adelante. Hacer de su vida actual, aquí y ahora un hecho nuevo y altamente significativo. Antes bien éste y su pueblo son ya estigmatizados como incapaces sociales y mendigos de un devenir histórico trágico. Un devenir histórico en el que se ven día tras día llamados a ser parte de un cambio social de talante individualista, resentido y superfluo. 
Individualista porque siempre piensan en función de nosotros los pobres; resentido porque siempre demonizan al otro, a la vez que día tras día se mueren de envidia por ser como éstos; superfluo porque su discurso no piensa en las condiciones reales de la emancipación social, cultural, doctrinal, y, ante todo, afectiva, de la condición de seres humanos auténticos, genuinos, en tanto en cuanto, la mejor de las emanaciones posible de la naturaleza. Si no, que, persisten en luchas fortuitas sobre la base de peticiones precisas que apuntan más a sus propios intereses que a las necesidades reales de toda una colectividad. Su lucha, como acontece en el mundo real, es una lucha por el círculo reducido de los igualmente necesitados. De tal modo que esta mirada es una mirada siempre inquisidora: el otro opresor, y el yo oprimido. Sin pensar nunca en que el opresor es oprimido por su condición dialéctica de necesidad de reconocimiento de alguien no igual a él (Hegel, 1971), sin contar con su malignidad por una vida plena, y el oprimido es opresor por su condición dialéctica de, ustedes los que poseen, los señores, sin contar con su propia malignidad existencial, su pereza de auto-transformarse en vencedores (Nietzsche, 2000).

La teología latinoamericana, como discurso de liberación, se plantea al margen de las realidades culturales y a favor del uso de las tecnológicas de nuestro tiempo. Está al margen de las realidades sociales porque habla de pobres y desposeídos en contextos en donde la gente vive feliz aprovechándose de su situación social, por medio de la acción de mendicidad constante, ante Estados de bienestar que, en lugar de plantear proyectos de inclusión a nivel social, político, artístico, cultural y afectivo, promueven situaciones puntuales de mendicidad. Un caso concreto la hayamos en la ciudad de Cali en las comunas trece, quince y veintiuno donde los desplazados por la violencia prefieren no trabajar ni hacer nada para obtener del Estado ayudas económicas de toda índole, situación que les permite vivir en un auto-estado de marginación y mendicidad constante promovido por propuestas como ésta, la teología de la liberación, donde la condición de pobreza económica asegura un subsidio de vida, en lugar de una vida plena, positiva (Nietzsche, 2000, p. 35-55). 
La teología de la liberación se plantea a favor de los avances tecnológicos porque no hace una reflexión social, cultural, artística, biológica, psicológica y afectiva de lo que éstos producen al interior de una comunidad y en la vida de un individuo. A tal punto que ella promueve un uso de la tecnología exacerbado, porque en esto consiste la liberación, en crear situaciones iguales de uso de las TIC, sin previos procesos de evaluación, investigación y reflexión, al interior de cada pueblo en su concreción real.

En síntesis, la Teología de la Liberación es un discurso de poder como otros, en el que desaparece por completo una real preocupación por el otro, la humanidad en todo su ser y su sentir, y no tan sólo a los mal llamados pobres, desprotegidos u oprimidos, sino a la totalidad de actores sociales que realmente quieran ser emancipados. Pero peor aún, la teología de la liberación se plantea desde la malignidad de la propia acción demoniaca judeo-cristiana, por lo que queda la pregunta por ¿cómo una ideología que ha sido adoctrinadora, excluyente, sexista y racista, se impone como una propuesta de liberación? Esto no nos parece más que una gran broma, una tomadera de pelo como otras más de la historia occidental.

\section{El acontecimiento}

Intentaré pensar un tema, que opino, ocupará el siglo XXI: la aceptación por parte de cada una de las tradiciones regionales filosóficas del planeta (europea, estadounidense, china, hindú, árabe, africana, latinoamericana, etcétera) del valor y de la historia de las otras tradiciones filosóficas [...] Será un proceso de mutuo enriquecimiento filosófico que exige, éticamente, reconocer a todas las comunidades filosóficas de otras tradiciones con iguales derechos de argumentación, superando así un moderno eurocentrismo hoy imperante, que lleva a la infecundidad y, frecuentemente, a la destrucción de notables descubrimientos de otras tradiciones. (Dussel, 2010, p. 119-120)

No existe en Latinoamérica algo así como una filosofía de la Liberación. Y no existe por tres motivos precisos: el primero, porque Latinoamérica no es una unidad étnica, racial, cultural, económica, social, política, y, ni si quiera, territorial. Latinoamérica 
es una masa amorfa, heterogénea, simbiótica, de distintas prácticas, saberes y acciones organizacionales de distintos pueblos, únicos, diferentes, conflictivos. El segundo, porque lo que desde la década de los años sesenta que el Dr Enrique Dussel ha venido vendiendo, como filosofía de la Liberación, no ha sido más que un doble proceso: a) la renovación, colonial, en otro espacio geográfico, de un pensamiento judío, la dialéctica doxológica del Talmud vuelto psicología, sociología, teología, criticismo, existencialismo, estructuralismo, etc. Lenguaje, ideas, y conceptos que han sido trasladados al campo de la filosofía por autores como $\mathrm{E}$ Dussel; P. Freire; B. Soussa, entre otros.

A partir de mediados del siglo, un creciente número de escritores judíos latinoamericanos han enfocado en sus textos, alternativa 0 simultáneamente, temas judíos, latinoamericanos y universales. Pero más importante que su cantidad es su creciente visibilización y su busca de una definición de pertenencia literaria que no sea ni aislacionista ni apologética. Esa voluntad de visibilización, particularmente notable en los años ochenta y comienzos de los noventa, generó una conciencia de grupo y la tendencia de los escritores a reunirse y debatir una problemática percibida como común (Goldberg, 2000, p. 312).

b) el "éxito" de los movimientos revolucionarios de américa latina, todos y cada uno apoyados, financiados, pensados, proyectados, por dineros transnacionales, extranjero, banquero. Toda diferencia fue borrada, toda acción social fue manipulada, todos los discursos dirigidos y toda posibilidad agotada.

La larga senda hacia la segunda emancipación latinoamericana (meta en el largo plazo de la filosofía de la liberación), cuyos peldaños son las revoluciones contemporáneas; la cubana (1959), a la que le seguía la revolución democrática socialista de Allende (1970), y posteriormente continuará con la revolución sandinista de 1979, la zapatista de 1994, la boliviana de 1999 , la boliviana en el 2006, la paraguaya de 2008, y otras tantas movilizaciones populares que serán hitos. (Ortíz, Zuñiga, Galindo, González, 2009, p. 401) 
Acción que, realmente, tenía como objetivo la concreción de un mundo global en tres dimensiones: uno, el modo de vida burgués (Weber, 2000) como el único modo de vida posible; dos, la red, como el único espacio de interacción social posible; tres, la condición existencial de ser consumidor como el único modo del existir.

c) la confusión ontológica propia del acontecer cosmovisivo de cada pueblo, y sobre el que los "filósofos de la liberación" han puesto el rótulo conceptual, arbitrario, de filosofía. Ejemplo de hecho lo constituyen el mundo indígena, negro y chino: el pensamiento indígena está atado esencialmente a la relación recíproca entre la divinidad y el territorio, no es filosofía, es un pensar que deviene de otro modo. En las prácticas comunitarias orientadas por los sabedores, y la relación que la misma guarda con la naturaleza ya que esta está animada por la divinidad, no es filosofía, es otra cosa. Sin la idea metafísica de la divinidad, propia de cada comunidad indígena, y el territorio, en donde emana la divinidad, no hay la posibilidad de un pensamiento indígena, ya que la identidad de su acontecer se perdería, y eso no es filosofía, es otra forma de emerger del pensar.

Para los nativos que se autodenominan como Kamuéntsa Yentsáng, Kamëntsá Biyáng "hombres de aquí, con pensamiento y lengua propia" del Valle de Sibundoy, en el departamento del Putumayo, sus saberes provienen de Bëngbe Bëtsa "nuestro creador, nuestro mayor, nuestro grande", y de Tsbatsan mamá, que es su "madre tierra", e identifican su lugar de origen como Bëngbe Tabanók, significando "nuestro lugar de partida y llegada". Kem luar, para expresar "este territorio". (Muchavisoy, 1997, p. 66)

El pensamiento negro, por su parte, está atado a la música, vuelta canto y danza. Sin territorio el pensar negro fue capaz de metamorfosear el dolor gracias a su sentir la vida desde el ritmo. Sin este, lo negro hubiese desaparecido. La música, el ritmo, vuelto canto y danza, actúa como memoria viva que repara, conserva y dinamiza: repara el hecho trágico de la esclavitud, conserva el saber ancestral, y dinamiza el mundo ancestral. Lo cual, desde luego no es filosofía, es otra forma de interacción con el mundo. 
Tenía siete años apenas, apenas siete años. Qué siete años, no llegaba a cinco siquiera [...], de pronto unas voces en la calle me gritaron negra, negra, negra [bis] ¿Soy acaso negra me dije?, ¿qué cosa es ser negra? Yo no sabía la triste verdad que aquello escondía, negra, y me sentí negra, como ellos decían. Y retrocedí, como ellos querían. Y odié mis cabellos y mi las labios gruesos, y mi diapelada, y mi carne tostada, y retrocedí. Negra, y retrocedí, negra [bis] Y pasaba el tiempo, siempre amargada, seguía llevando a mi espalda mi pesada carga; y cómo pesaba [...] Me alargué el cabello, me empolva la cara, y entre mis entrañas siempre resonaba la misma palabra: negra, negra [bis] Hasta que un día que retrocedía, retrocedía y que iba a caer, negra [bis], ¿y qué?, ¿y qué? Sí, soy, negra, negra soy [bis], de hoy en adelante no quiero, alisar mi cabello, no quiero, y voy a reírme de aquellos que por evitar según ellos, que por evitarnos algún sin sabor, llaman a los negros gente de color; y ¿de qué color? Negro, y que lindo suena, negro, y que ritmo tiene, negro, negro, negro, negro, negro, negro [...] Al fin, al fin comprendí, ya no retrocedo, al fin, y avanzo segura, al fin, avanzo y espero, al fin; y bendigo al cielo porque lindo dios que negro azabache fuese mi color, y ya comprendí, al fin, ya tengo la llave negro, negro [bis] negro soy. (Santa Cruz, 2008)

El pensamiento chino, por ejemplo, está atado al fluir. Su vida se rige por unas coordenadas simples: una energía vital que todo lo dinamiza, el Chi. Esta se expresa de un doble modo, en una polaridad Ying, que es una representación teórico-práctica, de lo femenino, y en una polaridad Yang, que es una representación teórico-práctica de lo masculino. Desde luego esta forma de ser no es en modo alguno filosofía, es un modo muy específico de relación con lo vivo. Más aún, cuando en tal cosmovisión se imponen cuatro niveles de formación marcial: el Tai yu o vacío, en tanto vaciarse; el Wu Chi o limpieza, en el sentido de purificarse; el Tai-chi o movimiento, flujo de contracción y expansión del movimiento; y finalmente, el Tai yi, o gran motor, que en sentido estricto sería explosión creativa. Desde luego, nada de esto es filosofía, es, ante todo, una práctica de vida, cuya dimensión epistemológica escapa al racionalismo occidental. 
La ontología judía, en cambio, está atada a la palabra sustentada en la acción divina. Su pensar dentro del mundo, por el mundo y para el mundo es demagogia: ejercicio acucioso y sistemático de divagar sobre el fenómeno Dios. Fraseología, especulación lingüística de hacer circular la palabra, en torno a un pensamiento, completamente carente de definición conceptual, suplantado por artilugios argumentativos, tropos, metáforas, metonimias y demás. Tal ejercicio doxológico, no es desde luego filosofía, es palabrería obsoleta. La práctica taoísta del silencio les sienta mal. Compréndase entonces, que es desde este pensar fraseológico, que desde el siglo XIX, nacieron las ciencias humanas como monumentos vivos de esta práctica talmúdica. Las ciencias humanas han de hacer del hombre su objeto de estudio (Foucault, 1976) con el ánimo de problematizarlo, no para conocerlo, sino para desarticularlo de su relación fundante con: la tierra, la naturaleza, y su espiritualidad. De cada ciencia se ha aprendido algo: el temor por lo otro, lo diferente, la totalidad.

Los escritores judíos están destinados a la soledad y al cosmopolitismo, más que otros escritores. Se abstienen más que otros de todo lo que pueda parecer una pertenencia colectiva exclusiva a un país. Se resisten a las "raíces", al "inconsciente colectivo", al "espíritu del pueblo". En una palabra, a todo lo que sea "comunidad". (Lévy, 1987, p. 12)

Si realmente se quisiera hablar de una Filosofía de la Liberación debería entonces, para ser consecuentes con la hipótesis principal de estos, hacer un proceso de decolonización en cuatro niveles. En un primer nivel decolonial (Sousa, 2010) el lenguaje con que Latinoamérica ha pensado el mundo habría de ser reformulado, pues es bien sabido que las categorías lingüísticas con que estos pensadores han desarrollado sus propuestas teóricas están preñadas de un lenguaje completamente eurocéntrico. El sólo pensar en la categoría de filosofía es ya de antemano forzar a un pueblo que jamás elaboró dicha categoría a adueñársela sin entender la dimensión epistemológica de la misma. Así, sostener, que los egipcios hicieron filosofía, los chinos, los persas, los indios, etc., sin entender la dimensión lingüístico-cultural que los griegos le dieron a tal expresión, es desconocer que en los pueblos ya enunciados no había filosofía simplemente porque la expresión es 
griega, y con ello estos significaban algo muy puntual. En oposición a esta consideración léxica hay que decir que los otros pueblos no hicieron filosofía, hicieron otra cosa. Pensaron el mundo de un modo completamente diferente a como lo hicieron los griegos. No se está diciendo aquí que los otros pueblos no hayan elaborado unos sistemas de pensamiento propios de sus realidades sociales e históricas, porque de hecho lo hicieron. Pero a distintas formas de pensar el mundo estos pueblos daban significaciones léxicas diferentes, y tales enunciaciones no significaban necesariamente lo mismo que significaba la expresión Filosofía para los griegos. Los sabios persas, los sacerdotes egipcios, los maestros chinos, los rabinos hebreos no eran filósofos en el sentido griego del término; los primeros eran astrólogos, teósofos y con ello, otra cosa, no filósofos; los segundos eran teósofos, alquimistas, astrólogos y con ello, otra cosa, no filósofos; los terceros eran médicos, alquimistas, artistas marciales, y con ello, esto, maestros, no filósofos; los últimos eran esencialmente demagogos, no filósofos. La filosofía en su origen, en el contexto de los presocráticos, es una cosa muy simple: un proceso de racionalización sobre el saber teosófico de otros pueblos, y con ello, es otra cosa; y es otra cosa, no simplemente porque el ejercicio de filosofar ya implica la necesidad de sistematizar desde la razón, y a expensas de cualquier voluntad ajena a ella; sino, y más importante aún, es que, en la dimensión corporal, ética, política y social de los filósofos frente a los otros pensadores era completamente distinta, ni mejor, ni peor, diferente. La definición de la filosofía como amor a la sabiduría, cabe aclarar, es más bien una definición un tanto tardía, acuñada en un periodo posterior, aunque, supuestamente atribuida a Pitágoras. Lo segundo que habría que decolonizar o, descolonizar (Soussa, 2011), sería el pensamiento mismo. Si la configuración orgánica de un pensamiento es la unión motivacional del medio familiar, el entorno vecinal y el contexto socio-cultural que le llegan a un infante a través del proceso lenguaje-familia, lenguaje-escuela, lenguaje-oficio, las imágenes, los conceptos, las categorías, los enunciados, los discursos, los relatos, los sentires, los padeceres, los sueños, las motivaciones, todas están predeterminadas, y con ello, colonizadas. Si todos están colonizados el pensamiento mismo está anclado a la historia de una cultura. Su descolonización implicaría el vaciarse de esta. Ello implica, olvido y re- 
aprensión. La cuestión es ¿con qué pensamientos ha de ser nuevamente resignificado el cerebro?, si la respuesta es con la nueva forma de des-colonialismo o decolonialismo ¿esto no es otro tipo de colonialismo?, ¿un colonialismo de la periferia? Ahora, si hemos de adentrarnos de lleno en un proceso histórico de descolonización cultural a nivel del pensamiento, entonces ¿cada cultura que ha sido colonizada por procesos internos de dominio habrá, necesariamente, de hacer el mismo proceso? Es decir, en todos los pueblos del mundo operaron procesos históricos de conquista: África, China, India, América, al interior de cada una de estas regiones, hubo un grupo humano que se impuso sobre los otros a través del uso de la fuerza militar y fundó en, lo que consideraron su propio territorio, un imperio. Ningún imperio del mundo se ha forjado con el diálogo o la paz. En África los Zulu, los Bantu, los Yoruba, en China los Chin, en India los Pandabas, en América los Mayas. Todos estos pueblos tuvieron algo en común: eran pueblos divididos entre sí, en su interior, e hicieron de la conquista por la fuerza el móvil de su razón de ser: la guerra y el asedio violento como motor de su civilización. No existió en el mundo antiguo una unidad homogénea llamada África, China, India, América. Cada uno de ellos vivían socialmente en situación de guerra. Las guerras tribales, provinciales o entre ciudades, eran la constante del mundo antiguo. Por lo que, cada pueblo habría de darse a la tarea de aplicar sobre su propia historia de conquista una tarea descolonizadora, para poder hallar las raíces de su propio pensamiento.

En tercer lugar, si se hace un proceso de descolonización del lenguaje, del pensamiento, ello trae consigo de un modo necesario una descolonización de la ética con que el propio pueblo ha construido: las relaciones del cuerpo con el cuerpo, del cuerpo con el otro, a nivel sexual, matrimonial, familiar; y las relaciones del cuerpo en el contexto social, cuerpo-escuela, cuerpo-oficio. Un pueblo no es sólo el corolario de expresiones y pensamientos, es también la manifestación ética del modo en que han considerado el cuerpo como objeto de culto, instrumento o consumo. Por ello, toda descolonización habría de pensarse también, desde la posibilidad misma de descolonizar las imágenes con las que la colonia ha pensado el cuerpo; en occidente esto implicaría ante todo un examen del por qué el cuerpo 
que poseemos en un cuerpo moral. Y, moral en términos completamente judeocristianos.

\section{Conclusiones}

El flujo del pensar que en este escrito se dio, problematizó el fenómeno académico intelectual denominado filosofía de la "liberación". En este, se logró demostrar las paradojas que subsisten en su interior, como el poco impacto de sus presupuestos teóricos: se hizo una disertación sobre dos de los campos disciplinarios que le dieron origen, la pedagogía crítica y la teología de la liberación. En los dos casos se evidenció que sus reflexiones no han sido sino un discurso académico intelectual, para brindarle a las masas la ficción metadiscursiva de un mundo posiblemente mejor. Ficción, que el estilo de vida burgués, la conquista del espacio por la red, y el único modo de ser, el ser consumidor, propios de un mundo global, agotaron la posibilidad de toda crítica, y con ello, de cualquier transformación.

El enfrentamiento con los supuestos conceptuales de esta forma del pensar arrojó como resultado una acción del pensamiento que podría ser ad infinitum. Pues, si realmente se quisiera rehacer la historia, re-pensando la historia, el lenguaje, los conceptos, los pensamientos sobre el mundo, tendrían que ser todos completamente descolonizados.

Finalmente, la filosofía de la "liberación" no ha sido posible debido a: primero, se hizo del pensamiento europeo un pretexto para justificar el academicismo doxológico judío que pervive en su arquitectura teórica, se judaizó la realidad Latinoamericana, lo indígena, lo negro, son leídos desde el ejercicio especulativo talmúdico. Segundo, se hizo notar en este ejercicio de caligrafía experimental, la falta de entendimiento que hay, de parte de los defensores de una filosofía de la liberación, de otras ontologías, o formas de ser, o pensar el mundo y que son juzgadas como filosofía, el pensamiento indígena enraizado en la dialéctica divinidad-territorialidad; el mundo afro dominado por el ritmo vuelto canto y danza; el modo de vida chino vuelto flujo de energía. De modo tal, que la deconstrucción histórica del proceso de dominación sobre los oprimidos debe hacerse, incluso, al interior del horizonte cosmovisivo de los pueblos que le dieron origen al continente. 
Jony-Alexis Rengifo-Carpintero; Carmen-Helena Díaz-Caicedo

La emergencia de lo indígena y lo afro, sus imperios, sus lenguas, su saber, su cosmovisión han de ser revisadas, debido a que al interior de estos también se dieron procesos de dominación, exclusión, marginación, imposición y conquista. La descolonización habrá de operar, entonces, al interior de todo proceder humano que haya arrojado como resultado algo llamado cultura.

\section{Referencias}

Chervel, A. (1991). Historia de las disciplinas escolares: reflexiones sobre un campo de investigación. Revista de Educación, 295, 59-111

Corea, C., Lewkowics, I. (1995). Pedagogía del aburrido. Buenos Aires: Paidós

Dussel, E. (2010). El siglo XXI: nueva edad en la historia de la filosofía en tanto diálogo mundial entre tradiciones filosóficas. Signos Filosóficos, XII (23), 119-140

Foucault, M. (1979). Vigilar y castigar. Buenos Aires: Siglo XXI

Freire, P. (1971). La pedagogía del oprimido. Barcelona: Siglo XXI

Goldberg, F. (2000). Literatura Judía Latinoamericana: modelos para armar. Revista Iberoamericana, LXVI (191), 309-324

Gutiérrez, G. (1968). Hacia una Teología de la Liberación. Madrid: Puigcerda

Gonzales, W., Poulain, J. (2006). Transformaciones contemporáneas de la filosofía. Cali: Universidad del Valle Habermas, J. (1999). Teoría de la acción comunicativa. Madrid: Taurus

Hegel, M. (1971). Fenomenología del espíritu. Buenos Aires: Paidós

Juls, P., Legrand, L. (1999). Grandes orientaciones de la pedagogía contemporánea. Madrid: Narcea

Kant, E. (1985). Pedagogía. Bogotá: Rosaristas

Lévy, B.-H. (1987). Existe-t-il une littérature juive?. Le Figaro Magazine, 390, $12-13$

McLaren, P. (1991). Pedagogía crítica, resistencia cultural y producción del deseo. Buenos Aires: Aique

Muchavisoy, J. (1997). Los saberes indígenas son patrimonio de la humanidad. Revista Nómadas, (7), 64-72

Nietzsche, F. (2000). Schopenhauer como educador. Barcelona: Gedisa

Quiroz, Á. (1980). Eclesiología en la Teología de la Liberación. Barcelona: Tuquest

Ricard, R. (2013). La conquista espiritual de México. México: FCE

Santa Cruz, V. (2008). Me Gritaron negra. Youtube

Scannone, J. (2009). La filosofía de la liberación: historia, características, vigencia actual. Teología y Vida, L, 59-73

Silva, S. (2009). Teología de la Liberación. Revista Teología y Vida, 50, 93-116

Sousa, B. (2011). Epistemologías del sur. Revista Internacional de Filosofía Iberoamericana y Teoría Social, 54, 17-39

Weber, M. (2001). Sociología de la religión. Buenos Aires: Siglo XXI

Zuluaga, O. (1996). Pedagogía e historia. Medellín: Universidad de Antioquia 